\title{
Influenza in Madrid, Spain, 1991-92: validity of the sentinel network
}

\author{
M A Ordobás, B Zorrilla, P Arias
}

\begin{abstract}
Objectives - The aim was, firstly, to study the validity of the sentinel network data by analysing the correlation between the weekly influenza cases detected by the network and the number of cases notified to the compulsory disease notification system and, secondly, to describe the epidemiology of the period 1991-92 in terms of the sentinel network data.

Design - The study design was descriptive.

Subjects - The population resident in the city of Madrid.

Main Results - There was a high correlation between the cases notified to the compulsory disease notification system and those listed by the sentinel network $\left(r=0.91, p<0.001, r^{2}=0.82\right)$. The epidemic activity during the period 1991-92 was centred approximately on week 48 in 1991 and week 6 in 1992 (24 November 1991-8 February 1992). Altogether 913 cases of influenza were notified through the sentinel network. The greatest number of cases occurred in people aged between 20 and 39 years.

Conclusion - For the epidemiological surveillance of influenza it is necessary to develop systems that can quickly detect epidemic periods and provide information about populations at risk, in addition to systems that isolate and identify seasonal epidemic viruses. Both types of data will help the development of adequate public health policies. Sentinel networks provide these data and offer additional advantages such as lower cost.
\end{abstract}

(FEpidemiolCommunity Health 1995;49(Suppl 1):14-16)

Influenza is a serious infectious disease that has a large impact in economic and health service terms. It causes epidemics with a high population incidence associated with increased mortality, particularly in those who are already ill or older than 65 years.

Influenza is a difficult disease with regard to surveillance and monitoring because the clinical characteristics which it presents are common to other respiratory viral infections (influenza-like diseases).

For epidemiological surveillance of influenza, different indicators can be used. ${ }^{1}$ These range from the specific ones, such as the identification and culture of the viruses, to the nonspecific but very sensitive indicators, such as the number of home visits made by general practitioners. An adequate monitoring pro- gramme should emerge from a combination of various complementary indicators. ${ }^{2}$

The usefulness of a sentinel network in surveillance and monitoring is widely recognised for influenza. ${ }^{2}$ It will enable characterisation of cases, and provide relevant information on factors such as the vaccination status or the appearance of medical complications.

The epidemiological surveillance of influenza in the community of Madrid is based on various data sources; primarily the numbers of the cases notified to the compulsory disease notification system and to the sentinel network, which started in February 1991. In addition, there is collaboration with the microbiological surveillance network, coordinated from the Instituto de Salud Carlos III supported by the Ministry of Health. This system analyses specimens collected in five primary care centres throughout Madrid from patients with acute respiratory symptoms or with suspicion of influenza, and allows detection and characterisation of the influenza virus circulating at each period. The epidemiological surveillance programme is completed by mortality data (number of weekly burials carried out in Madrid town).

This study aimed, firstly, to analyse the information from the sentinel network system, using the compulsory disease notification system as a reference, and secondly, to describe 1991-92 epidemiologically in terms of sentinel network data.

\section{Methods}

The population being studied comprised residents of Madrid (census 1991, 4950000 inhabitants). A cluster analysis was carried out to determine the constitution of the network, on the basis of which the community was divided into eight strata. These were made up of health sanitary districts, grouped by various demographic, sociological, and sanitary characteristics. The network was formed by 100 general practitioners and paediatricians attached to the national health service. Twenty of these practitioners (15 GPs and five paediatricians), proportionately distributed through the eight strata, notify influenza. The population covered by practitioners who notify influenza is 30800 .

Each week the sentinel practices notify by mail the following data on patients they have seen that may have influenza:

- Age;

- Sex;

- Clinical manifestations (rapid onset of fever $>39.5^{\circ} \mathrm{C}$, migraine, myalgia and/or general weakness, and respiratory symptoms); 


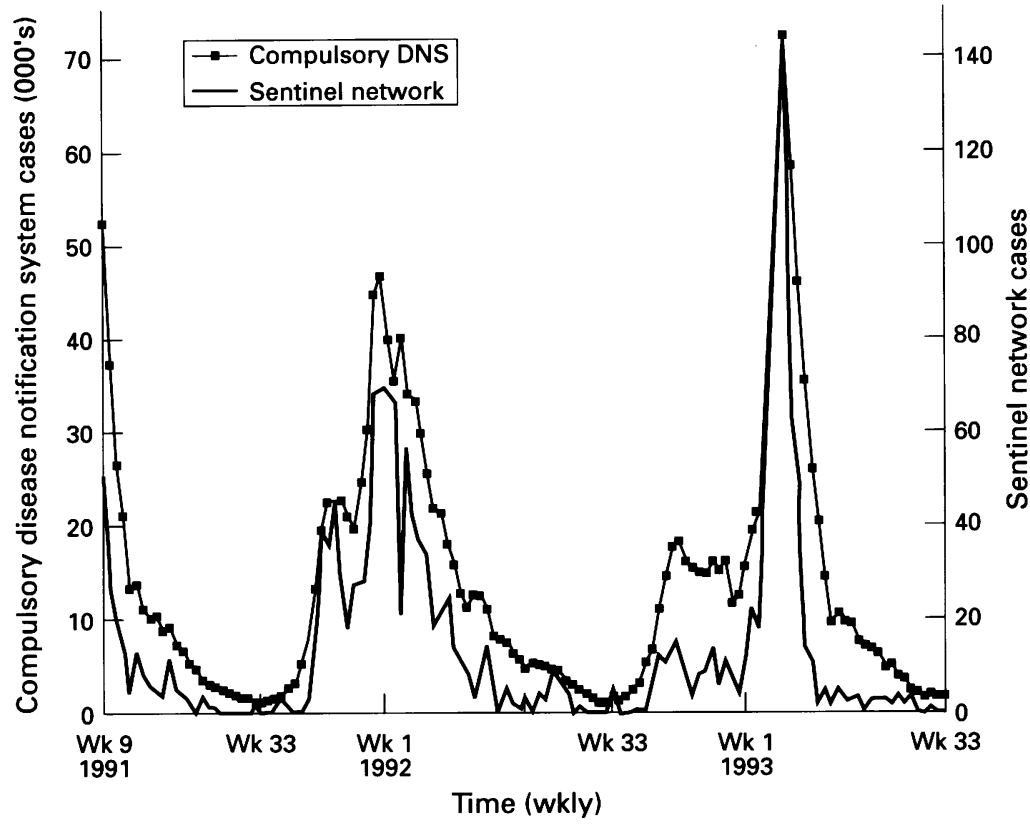

Weekly cases of influenza disease notified to the compulsory disease notification system and to the sentinel network. (Community of Madrid, 1991-93.)

- Previous abnormalities (none, circulatory or respiratory disorders, renal or metabolic diseases, immunodeficiency, and others);

- Complications (pneumonia and others);

- Vaccination status (vaccinated in current period, month of vaccination, not vaccinated, unknown);

- Derivation (referral to hospital or specialist).

A case is not strictly defined, there is only consensus about the symptomatology, common to other influenza-like diseases.

The compulsory disease notification system is the traditional Spanish system for epidemiological surveillance of communicable diseases. Influenza has been included since its initiation in the 1930s. It is a universal system, and is compulsory for all medical practitioners. They notify, on a weekly basis, the number of cases of communicable diseases, including influenza, that they have seen. In practice, only the medical practitioners attached to the national health service participate.

Data have been analysed by linear regression analysis, using the number of cases notified weekly to the sentinel network as the independent variable and the number of cases notified to the compulsory disease notification system as the dependent variable. The time period was February 24, 1991 (week number 9) to August 21, 1993 (week number 32), comprising 128 weeks. In addition, the results of the clinical and demographic characteristics of the cases in the influenza season 1991-92 have been presented. Demographic data have been compared with those of the 1991 national census of the community of Madrid. The epidemiological season defined for influenza begins in week 33 and ends in week 32 of the following year. The statistical analysis was carried out by means of the EpiInfo V.5 package.

\section{Results}

The average weekly notification coverage of the sentinel network during the period studied was $65 \%$, with a maximum of $95 \%$ and a minimum of around $50 \%$, corresponding to holiday periods (Christmas and summer). The registration forms were received in the central unit between one and five days after the end of the notifying week. The compulsory disease notification system had, for the same period, an average weekly coverage of $80 \%(70-85 \%)$ in primary care. The registration forms for this system were received in the central unit between one and three weeks after the end of the notifying week.

Both series present a similar pattern (figure). Both reach a maximum in the same weeks, corresponding to the epidemic peaks of each of the seasons. The epidemic peaks are between week number 48 in 1991 and week number 6 in 1992 and between weeks number 3 and 12 in 1993 (17 January 1993-27 March 1993).

The correlation coefficient established between the cases notified to the compulsory disease notification system and those notified by the sentinel network was $r=0.91(p<0.001)$, with a determination coefficient equal to $0 \cdot 82$. The linear regression equation is: $y=$ $543 x+6133(95 \%$ CI for $\beta$ coefficient $=497$; 589 ), where $x$ is the number of weekly cases declared to the sentinel network, and $y$ is the predicted number of cases in the compulsory disease notification system.

In the influenza season 1991-92, 913 cases of influenza were notified through the sentinel network. Of these, 472 were in women and 412 in men ( $p>0.05)$, and the age group with the greatest number of cases was that between 20 and 39 years. The age distribution of the

Characteristics of cases from the sentinel network: influenza season 1991-92

\begin{tabular}{|c|c|c|c|c|c|c|}
\hline & \multicolumn{6}{|c|}{ Age group (y) } \\
\hline & $0-9$ & $10-19$ & $20-39$ & $40-65$ & $>65$ & Total \\
\hline \multicolumn{7}{|l|}{ Sex } \\
\hline Male & 18 & 99 & 195 & 144 & 16 & 472 \\
\hline Female & 25 & 104 & 154 & 109 & 20 & 412 \\
\hline Unknown & 6 & 8 & 4 & 9 & 2 & 29 \\
\hline \multicolumn{7}{|l|}{ Percentage distribution } \\
\hline Study group & $5 \cdot 3$ & $23 \cdot 1$ & $38 \cdot 7$ & $28 \cdot 7$ & $4 \cdot 2$ & 100 \\
\hline Census, 1991 & $11 \cdot 0$ & $17 \cdot 0$ & $31 \cdot 3$ & $28 \cdot 8$ & 11.9 & 100 \\
\hline \multicolumn{7}{|c|}{ Clinical manifestations (\%)* } \\
\hline Fever & $91 \cdot 8$ & $94 \cdot 3$ & $85 \cdot 0$ & $79 \cdot 4$ & $52 \cdot 6$ & $84 \cdot 5$ \\
\hline Headache & 91.8 & $89 \cdot 1$ & $84 \cdot 1$ & $82 \cdot 4$ & $78 \cdot 9$ & $85 \cdot 0$ \\
\hline Myalgia & $83 \cdot 7$ & $88 \cdot 1$ & $95 \cdot 5$ & $95 \cdot 0$ & $89 \cdot 5$ & $92 \cdot 8$ \\
\hline Respiratory symptoms & $81 \cdot 6$ & 74.9 & $83 \cdot 3$ & 85.9 & $92 \cdot 1$ & $82 \cdot 4$ \\
\hline
\end{tabular}

* Cases can present with various clinical manifestations simultaneously. 
notified cases differed from that in the general population $(\mathrm{p}<0.0001)$.

The clinical profile is presented in the table. The clinical pattern varied according to the age group, so that the frequency of fever and migraine decreased as the age increased $(p<0.001)$, while myalgia and the respiratory symptoms increased in the same direction ( $p<0.001)$. In addition, $17 \%$ (156 cases) showed other associated clinical symptoms, of which most were gastrointestinal disorders.

In 64 cases $(7 \%)$, the existence of previous pathologies was known: $43 \%$ of these were respiratory, $33 \%$ circulatory, $22 \%$ metabolic, $9 \%$ renal, and $33 \%$ others. Of the cases notified, $8 \%$ (73 cases) were vaccinated for this period, and $10 \%$ were of unknown vaccination status. Complications were recorded in 26 cases (3\%), pneumonia in eight cases and other complications in 18. The most frequent complication was bronchitis, which occurred in 10 cases.

The viruses isolated during the epidemic period were of the $\mathrm{A} / \mathrm{H} 3 \mathrm{~N} 2$ and $\mathrm{A} / \mathrm{H} 1 \mathrm{~N} 1$ types, similar to those recommended for the vaccine during this period.

\section{Discussion}

The study period coincided with the beginning of the sentinel network, and during the first months problems with some members of the network produced a decrease in the notification coverage. This was subsequently overcome. The general practitioners who dropped out were randomly geographically distributed, so we believe that the sample remained unbiased, and that only its size was affected.

The Spanish national health service provides universal coverage in primary health care, with a geographically distributed population assigned to each general practitioner. This could allow us to estimate the incidence of the disease in the general population. The use of private medicine, self medication, and no requirement for medical care in mild forms of disease, together with the low coverage previously described, however, makes it impossible to estimate the incidence of disease.

The validity of the compulsory disease notification system in the epidemiological surveillance of influenza has been proved previously, ${ }^{3}$ and the coverage levels of this system remain steady enough. However, its low specifity is obvious. The epidemic period of influenza shown in the figure is surrounded by a great "basic wave" of influenza-like diseases, that starts in the autumn and is possibly linked to a fall in temperature and the start of the academic year. Specificity seems to be better in the sentinel network series, especially in the season 1992-93, when the "basic wave" is much lower than that of the compulsory disease notification system. The improvement in speci- ficity, together with the good correlation index show the usefulness of the sentinel network. In addition, the responsiveness of the system, the additional clinical and demographic data provided, and the smaller cost, produce a useful, reliable system of surveillance for influenza.

The clinical profile of the influenza cases detected in the sentinel network is characteristic of that in influenza disease. ${ }^{4}$ Age distribution may be affected by selective medical care demand according to age. The lower number of cases in children could be due to the use of private medicine, which is higher than in other age groups ${ }^{5}$ of the population. This could make children under represented in the sample. In the elderly, the reduced frequency of cases may be related to their previous immune history, in addition to periodical vaccination (influenza vaccination is freely offered to people older than 65 years).

With regard to information provided by other complementary systems of epidemiological surveillance, microbiological isolation of viruses is considered the gold standard in the detection of an epidemic period. ${ }^{6}$ In our study the epidemic periods detected by the notification systems coincided with the periods in which isolation of the viruses was undertaken. When virus isolation was not undertaken, no epidemic activity was detected by any of the systems.

Another data source is mortality, widely used in epidemiological surveillance of influenza; ${ }^{7-8}$ in the community of Madrid mortality is monitored through weekly burials. This method is very quick and has been validated in other studies. ${ }^{9}$ The authors thank general practitioners and paediatricians of the Sentinel Network: A Lorenzo, P Rabasa, J L Mora, I Vaquero, M C Sánchez, B Ibarrola, M García, M D Tolmo, M A Villanueva, R Ayuso, E González, M C Agos, D Cabezón, M J Santero, I González, M Soler, M R García, A del Pozo, $M$ D Garrido, M J Ruiz and Dr Pilar Pérez Breña from
CNMVIS. They also thank Dr Ray Jones for review of the manuscript.

1 OMS. Surveillance de la grippe-Region européenne. Rélève Epidémiologique Hebdomadaire 1992;67(8):49-50.

2 Hannoun C, Dad W, Cohen JM. A New Influenza Surveillance System in France: the Ile-de-France "Grog" I-Principles and Methodology. Eur 7 Epidemiol 1989;5(3): 285-93.

3 Perez Breña P, De Miguel C, Ordobás M, et al. Sistema de vigilancia para el estudio de la circulación gripal en Madrid vigilancia para el estudio de la circulacion gripal en Madrid 4 Betts RF, Gordon Douglas $R$. Virus de la Influenza. In: Mandell G1, Gordon Douglas R, Bennett JE, eds. EnMandell G1, Gordon Douglas R, Bennett JE, eds. En-
fermedades infecciosas. Principios y práctica. ed 3rd. Buenos fermedades infecciosas. Principios y práctica.
Aires: Médica Panamericana;1991:1377.

5 Ministerio de Sanidad y Consumo. Encuesta Nacional de Salud. Madrid: Ministerio de Sanidad y Consumo, 1989. Dad W, Quenel P, Cohen JM, Hannoun C. A new influenza surveillance system in France: The Ile-de-France "Grog" II-Validity of indicators (1984-1989). Eur f Epidemiol 1991 7(6):285-93

7 Serfling RE. Methods for current statistical analysis of excess pneumonia-influenza deaths. Public Health Rep 1963;78(6): 494-506.

8 Choi K, Thacker SB. An evaluation of influenza mortality surveillance, 1962-1979. II-Percentage of pneumonia and influenza deaths as an indicator of influenza activity. $A m \mathcal{F}$ Epidemiol 1981;113(3):227-35.

9 Borrell i thió C, Plasència i Taradach A, Thió i Fernandez de Henestrosa S, Marti-Recober M. Vigilancia epidemiológica de la mortalidad a partir de los entierros. Gac Sanit 1991;5(22):6-16. 